\title{
Turning Engineers into Reflective University Teachers
}

\author{
Isabel Huet ${ }^{1}$, José Tavares ${ }^{2}$, George Weir $^{3}$
}

\begin{abstract}
Increasing attention to quality and innovation in Higher Education (HE) is enhancing the pedagogic knowledge of faculty members and thereby encouraging the academic success of their students. This aim requires, from the institution and teachers, a greater degree of involvement than was previously the case. This is certainly borne out by experience in Portuguese universities. The growing concern of engineers with issues of pedagogy and academic success marks a sea change in the traditional conceptions of teaching and learning in Higher Education. There are, of course, indications that many academics are resistant to change. Our research indicates a tradition among Portuguese and Scottish academics to incline their effort toward research with a resultant decline in interest and effort on teaching. The present paper presents a meta-analysis of research conducted at the University of Aveiro (Portugal) and the University of Strathclyde (United Kingdom) between 2000 and 2004 involving academics who taught first-year introductory Programming courses. The purpose of our study was to promote reflection and research on teachingbased issues as a strategy toward improved student learning. The findings of the study raised a number of salient issues for discussion and consideration. In this paper, we present some of these issues, aiming to explore the impact that the findings may have on teachers' attitudes towards teaching and students' learning in introductory programming courses.
\end{abstract}

Index Terms - teaching best practices, reflective practice, student retention and failure, learning partnerships.

\section{INTRODUCTION}

Concern with quality and innovation in Higher Education is affecting teaching practices and focussing faculty attention on the academic success of their students. Greater rates of student success require a greater degree of involvement from the institution and its teachers, than was previously the case, at least, in Portuguese universities.

Today, we acknowledge a growing faculty concern with issues of teaching quality and academic success. Especially in light of the Bologna Process [26], quality of teaching has become a major concern across European institutions. In fact, the Bologna Process implies a similar structure with staged progression across Higher Education programmes and degrees, in order to promote student and academic mobility around Europe. It is important that Higher Education institutions reflect upon the quality of their teaching in order to successfully accomplish the common goals in European Higher Education. This political measure signifies a growing pressure to increase the quality of teaching in Higher Education institutions (as evidenced by QAA in the UK 'Quality Assurance Agency' for HE, and CNAVES 'Conselho Nacional de Avaliação do Ensino Superior' in Portugal). These demands are interpreted differently by different countries, institutions and programmes in accord with their own policies and priorities.

Due to the growing importance of teaching quality in universities, our research developed between 2000 and 2004 aims to promote reflection and research on teaching based issues to improve student learning. Underlining this purpose were the following objectives:

- to analyse the influence that teaching best practices might have on students' academic success (through the views of students and academics);

- to engage academics in educational research within their scientific area and have them reflect upon this experience.

- to promote a reflective university community on best teaching practices;

- to contribute to the development of HE knowledge.

Toward these objectives, a set of empirical studies were conducted in two different universities (Aveiro and Strathclyde). These studies represent continuous work carried out with academics and students of first year Introductory Programming courses, between the years 2000 and 2004.

The decision to work with first-year Introductory Programming courses and mainly centre on teachers arose from the findings of previous research [23] as well as from other arguments such as the low incidence of studies in this discipline, in contrast to other subject areas. Also, recent admission statistics have shown a massive growth in

\footnotetext{
${ }^{1}$ Isabel Huet, Department of Education, University of Aveiro, iza@dce.ua.pt

2 José Tavares, Department of Education, University of Aveiro, tavares@dce.ua.pt

${ }^{3}$ George Weir, Department of Computer and Information Sciences, University of Strathclyde, george.weir@cis.strath.ac.uk
} 
vocational courses in Higher Education. In particular, courses in software engineering and computer science have benefited greatly from this trend. Unfortunately, this trend has also been accompanied by an increase in student failure and drop out from the early years of many university courses [24, 27].

The Department of Educational Sciences and the Department of Electronic \& Telecommunications at the University of Aveiro (Portugal) have been working together with the Department of Computer \& Information Sciences at the University of Strathclyde (Glasgow, United Kingdom) since 2001. The main aim of this collaboration is to improve teaching and learning in introductory programming courses. The academic community across the University of Aveiro and the University of Strathclyde has a growing concern with student failure rates and academic achievement in first-year science and engineering courses.

\section{CONCEPTUAL FRAMEWORK}

Research indicates that 'enthusiastic teaching may lead to greater student involvement and commitment to the subject, while its lacklustre and rambling counterpart results in negative attitudes and a sense of futility' [17]. Nevertheless, further work suggests that a good performance or a 'colourful presentation' [17], does not necessarily mean good teaching and that students are often quite critical on this issue [20].

Teaching effectiveness is not easily described in terms of competences. Researchers agree that there is no single method for promoting good teaching. Indeed, the 'lecturer can adopt differing teaching methods, and offer all students pedagogy that suits them' [5]. Ramsden [17] explores six key principles for teaching effectiveness in Higher Education, as conceived by individual instructors: (i) interest and explanations; (ii) concern and respect for students and student learning; (iii) appropriate assessment and feedback; (iv) clear goals and intellectual challenge; (v) independence, control, and active engagement, and (vi) learning from students. The conjunction of these principles makes a lecturer effective, but the capacity to reflect upon these characteristics and the ability to change one or other aspect can distinguish the teaching quality of lecturers.

The ability to reflect on or about action, as well as to reflect about action reflection, helps individuals to analyse their actions, and reflect about the moment of reflection in action [21]. Each of these phases aims to achieve a deeper understanding of a specific educational phenomenon and is crucial for lecturer improvement and success.

An effective teacher must first engage students' interest, and motivate them toward a deeper understanding of the concepts being introduced. Furthermore, an 'effective teacher' should carefully prepare the exercises for each class and think about the best strategy to implement in the classroom. But, effective teaching is even more than class preparation or a list of specific activities. Blackburn \& Lawrence [1] refer to it as 'an art, a performance' that is difficult to measure. Effective teaching requires deep knowledge of the student learning process in order to transform students into active learners.
Some teaching strategies in the area of engineering have been explored by Felder \& Silverman [6], aiming to motivate and develop deep learning approaches in students and to turn them into reflective and active learners [12]. Nevertheless, different types of learners are more motivated by one strategy than another. The success of the implementation of any strategy lies in the lecturer's ability to combine activities that accommodate different types of students at different moments of the class.

Institutions around the world survey their academics to gather feedback regarding the relevance of effective teaching to themselves, to faculty colleagues, and to institutional faculty reward systems [2]. A study conducted by Brawner et al. (2002) with a group of engineering academics, revealed that effective and innovating teaching was mainly relevant to themselves and not so relevant for their colleagues, deans or department heads. The same authors concluded that faculty who work in developing new teaching methods are neither concerned with institutional rewards nor recognition from their colleagues, but are motivated solely toward their personal satisfaction.

\section{Methodology}

Bearing in mind the purpose, aims and objectives of our study, we chose a multiple case study approach [28]. There are several 'how' and 'what' questions, which justify an explanatory and exploratory case-study. Examples of such questions include: i) how do student perceptions of teaching effectiveness affect their motivation for the course and attendance at lectures?; ii) what are the views of lecturers regarding the effect that seminars, workshops, colloquia, team teaching (...) have as ways of rewarding, recognizing and ensuring good teaching?; and iii) how can the interaction between lecturers and educational researchers contribute to the improvement of best teaching practices?

In developing this study, quantitative and qualitative data were collected (i) from the analysis of archival records; (ii) from students (through surveys); (iii) by direct observation, and (iv) from instructors (through interviews and surveys) to better understand the organisation of the different courses and approaches to teaching and learning (Table 1).

TABLE I

MAP OF THE RESEARCH DESIGN: SOURCES OF DATA, TIME SCHEDULE AND SAMPLE

\begin{tabular}{l||l||l|}
\hline \multicolumn{1}{|c||}{ Sources of data } & \multicolumn{1}{|c|}{$\begin{array}{c}\text { University } \\
\text { of Aveiro }\end{array}$} & \multicolumn{1}{|c|}{$\begin{array}{c}\text { University } \\
\text { of Strathclyde }\end{array}$} \\
\hline \begin{tabular}{l|l|} 
Interviews \\
(academics)
\end{tabular} & $\begin{array}{l}\text { Informal interviews } \\
(2001) \mathrm{N}=19\end{array}$ & $\begin{array}{l}\text { Semi-structured } \\
(2002) \mathrm{N}=7\end{array}$ \\
\hline & $\begin{array}{l}\text { Semi-structured (2004) } \\
\mathrm{N}=7\end{array}$ & $\begin{array}{l}\text { Structured B (2004) } \\
\mathrm{N}=5\end{array}$ \\
\hline & Structured A (2004) N=7 & \\
\hline $\begin{array}{l}\text { Surveys } \\
\text { (students) }\end{array}$ & Survey 1 (2001) N=492 & $\begin{array}{l}\text { Survey 1 (2002) } \\
\mathrm{N}=101\end{array}$ \\
\hline & Survey 2 (2002) N=346 & Survey 2 (2003) N=62 \\
\hline & Survey 3 (2003) N=315 & \\
\hline $\begin{array}{l}\text { Survey } \\
\text { (academics) }\end{array}$ & Survey 1 (2004) N=5 & Survey 1 (2004) N=1 \\
\hline
\end{tabular}

October 28 - 31, 2006, San Diego, CA

\section{1-4244-0257-3/06/\$20.00 (C) 2006 IEEE}

\section{$36^{\text {th }}$ ASEE/IEEE Frontiers in Education Conference}




\section{FINDINGS}

Members of academic staff have been actively involved in trying to enhance the students' learning experience through reflection on teaching methods and trying new ideas to aid student success. During this process we have assimilated insights on teaching philosophies, methods and suggestions for course redesign. As an important piece of the 'puzzle', students also provided useful feedback on differing aspects of teaching and course organisation.

\section{Effective Teaching and Students' Academic Success}

Working with engineering staff was challenging work. The idea that engineering academics are not sensitive to educational research or pedagogy was not evident from this study. From the outset, academics exhibited concern with the causes of low student retention and academic failure. Academics also demonstrated a strong interest in knowing how their foreign colleagues approached teaching, how different courses and curriculum designs could affect teaching approaches and what would be the impact of teaching best practices on the student learning outcome.

One of the questions addressed in this study was whether students' perception of teaching effectiveness would affect their attendance at lectures, expectations and motivation for the course (Survey 1, 2, 3, 5 and 6). Findings from both universities suggest that such perception affects both students' attendance at lectures and their expectations of the course. In addition, at the University of Aveiro, different lecturers influenced students' perception about teaching and consequently their attendance at lectures and motivation for the course. This situation helps to explain why some lecturers would have more students in the class than others.

If it is accepted that effective teaching can enhance the quality of student learning, then academics have a great responsibility in this process [16]. Furthermore, it is important to ask the following question: What is the role of university teachers in Higher Education and what characterizes an effective teacher? Of course, university teachers are expected to be scientifically accurate and pedagogically efficient. An effective teacher is expected to encourage students to find questions worth pursuing, to engage students in continuous work and to encourage deep learning.

These goals are not always easy to achieve, especially when the majority of engineering academics have never attended a formal course on education and have no deep knowledge of students' approaches to learning. This situation is apparent both in Portugal and UK. Wankat \& Oreovicz [25] characterise a good teacher when he or she is able to conciliate a good performance with a good scientific content. According to the authors [25], a good performance requires from the academics an effort to stimulate the students' interest in the subject. Furthermore, effective academics should be clear, well-organized, approachable, and enthusiastic, as well as valuing learning, and keen to promote a student-centered orientation to learning.

\section{Auto and Hetero Evaluation of Teaching Effectiveness}

Student views on best teaching practices gave lecturers an idea of their performance as teachers, but this insight does not necessarily improve teaching. Ideally, lecturers should actually reflect upon that information and make necessary changes [4].

In this study, academics were informed about the students' perceptions of their teaching best practices, expectations and organization of the course. This feedback relates to the findings of surveys 1 and 5. In addition, the data were compared with academics' own perceptions of teaching best practices. The aim of this comparison was to provide diagnostic feedback to faculty on the effectiveness of their teaching and to create an opportunity for reflection on their practice.

Some authors suggest that appropriate feedback can promote students' learning and motivation $[8,17]$. In addition, instructional feedback can also modify instruction [22]. This study took in consideration the need to deliver feedback to teachers regarding the students' evaluation of their teaching practice. The students' feedback was extremely helpful in providing sufficient detail to help academics determine what was and was not working in their instruction. On the other hand, feedback allowed our academics to be more participative in the research. The first stage of interviews revealed that academics felt disappointed with some educational research, namely through the lack of feedback from the questionnaires that were circulated in the classes.

According to one lecturer, the questionnaire data are pertinent when leading to a reflective process. Statistical data indicate trends in students' answers. Therefore, it is important to reflect upon and discuss such trends and implement strategies to overcome some of the negative results.

Five of the lecturers in Aveiro admitted they did not dedicate much of their time to reflecting on this issue or even to exchanging information with colleagues who teach the same subject. From this perspective the interaction with the lecturers was crucial to initiate a turning point in their attitude towards teaching.

The academics' perception of their teaching (surveys 4 and 7) was slightly different from the students'. Lecturers had difficulty in understanding the students' learning process and motivation. Enthusiasm for lecturing was also discussed. Only two lecturers considered enthusiasm for the subject important to grab the students' motivation and interest in the lectures. Other members of staff played down the influence of this variable on students' behavior.

\section{Methods for Rewarding, Recognizing and Ensuring Good Teaching}

The structured interview (A and B - Table I), was adapted from the 'Survey of Academic Staff' [18] with the aim of analyzing academics' views on the effectiveness of some ways of rewarding, recognizing, and ensuring good teaching.

\section{1-4244-0257-3/06/\$20.00 C 2006 IEEE}

October 28 - 31, 2006, San Diego, CA

\section{$36^{\text {th }}$ ASEE/IEEE Frontiers in Education Conference}


The interview comprised 17 items ranging across a scale of 1 (no effect) to 3 (a great effect). Academics in both institutions mentioned the most effective processes would require greater account of teaching in the promotions process and as less effective processes, the attribution of rewards for the most effective academics. Also, data gathered from interviews revealed that workshops and seminars would be the most suitable means of promoting teaching best practices. Nevertheless, most lecturers questioned the value of workshops and seminars delivered by educational experts who lack a scientific or engineering background. Too much theory, not applied to practice, was the negative view of many of these seminars and workshops. The training of university teachers would depend on three factors: (i) the expert who would deliver the training or the keynote speaker at a seminar or workshop, (ii) the ability or competence for teaching of each individual lecturer, and (iii) the expected objective for the teaching training.

\section{Teaching Approaches in Engineering}

There are numerous approaches to the teaching of programming and the evaluation of programming ability [13]. Each of these approaches has benefits and drawbacks [3]. In spite of the time allocated for labs, the traditional style of lecturing is still the common method for teaching engineering at the Universities of Aveiro and Strathclyde.

The students' suggestion for teaching the course revealed that academics should present 'real-world examples' in which future engineers were required to understand the phenomena and solve problems (PBL- Problem-based Learning). The preparation of $\mathrm{PBL}$ is a teaching strategy crucial for developing skills and confidence in students designing a problem. These students 'are learning a process which will be an essential part of their work as professionals' [17]. The ability to think autonomously and in cooperation with other students is an essential characteristic for engineering students. The exercises conceived and planned for each course should relate the subject to the real world, so that students have a stake in solving the problem.

The importance of flow of information is identified by students and by lecturers and is seen as a consequence of the curriculum organization of the course. Nevertheless, the delivery of information should follow the steps of scientific method: (i) induction, (ii) inference from facts, observations or data, (iii) generalities (rules, theories, mathematical models) and (iv) deduction.

The spread between concrete information (facts, observations, experimental data and applications) and abstract information (concepts, theories, mathematical formulas and models) should be balanced in delivering the courses. Academics often refer to the difficulty of introducing abstraction. When abstraction is introduced in a class without considering the cognitive structures of the individuals, it is unlikely that that the new material will be transferred to long term memory [7].

Much research supports the notion that an inductive teaching approach promotes effective learning [6] which 1-4244-0257-3/06/\$20.00 @ 2006 IEEE includes increased academic achievement and enhanced abstract reasoning skills, longer retention of information, improved ability to apply principles, confidence in problemsolving abilities and increased capability for inventive thought.

Indeed, the findings suggest that academics should provide effective concrete material in class for those students who experience more difficulty to engage in the learning process. Visual illustrations and demonstrations are perceived as more effective than verbal information by the students (sensor learners). Sensors are more comfortable with concrete information than with abstraction and the converse is true of intuitors. Most engineering undergraduates are sensors and most engineering professors are intuitors [19]. Furthermore, lectures should balance abstract and concrete information in a way that ensures all learners engage actively in the class. This balance is the most difficult teaching goal.

\section{PARTNERShips OF LEARNing}

From the outset of this study, lecturers from both institutions expressed interest in being updated with results of the research and sought to discuss the findings with the researcher. In addition, appropriate feedback was given through the organization of seminars and individual meetings. One major objective addressed in this study was accomplished, since academics showed an increased interest in pedagogical issues, and some actually participated in educational research projects. As an outcome of this activity, we have three papers published at international conferences, involving engineers, and seminars have been held at the Universities of Aveiro and Strathclyde [9,10,11]. This joint work proved positive in establishing opportunities for lecturers to reflect on teaching practice and consider strategies for improving their teaching performance.

\section{CONCLUSION}

This study reflects the aims expressed by Melo, Silva, Gomes, \& Vieira [15]: (i) to contribute to a better consciousness of students and teachers regarding the factors that influence the quality and success of teaching; (ii) to promote a more participative and responsible attitude among students, and (iii) to provide accurate data to teachers in order to readjust contents and teaching methods, aiming for a reflective and self-critical attitude towards teaching.

What were the practical consequences of the study for the academic community? The most important was to create an opportunity for engineering academics to discuss issues related to teaching and learning.

Some academics participated more actively than others, but the majority accepted the relevance of the study toward a better understanding of academic success in introductory programming courses. Do we now have more reflective teachers? We believe so. Faculty spent hours over the last three years discussing and reflecting on these issues.

October 28 - 31, 2006, San Diego, CA

\section{$36^{\text {th }}$ ASEE/IEEE Frontiers in Education Conference}


Literature suggests that such attitudes help in recognising the learning needs of students.

Students' evaluation of teaching practice is accepted by several authors as giving students a more participative and responsible attitude towards learning [14]. Students are 'extremely astute commentators on teaching' [17]. Indeed, these students spent some of their time responding to questionnaires but they had no more active role in the study. We aimed to collect students' feedback as a complement to the study.

We believe that the evaluation of teaching by peers and students, along with external audits, are essential requirements for valuing teaching in Higher Education. This view is shared by Melo, Silva, Gomes, \& Vieira [15], who defend teaching evaluation as essential for attributing meaning to university pedagogy and to dignify the job of teaching in Higher Education.

Teaching practices might influence students' motivation towards learning either positively or less positively. Findings from the present study demonstrate that less effective academics can have a negative effect on student motivation, while more effective academics can enhance student motivation. These finding emphasise the relevance of teaching for student motivation and consequently, for their academic success. Furthermore, the work developed with academics regarding teaching practice is essential for improving the quality of learning in Higher Education.

Students in this study do not question the scientific knowledge of academics but may doubt their pedagogical expertise. This issue is an important problem in Portuguese and Scottish Universities. The effort of teachers to demystify their courses may take some years. Faculty members are nevertheless optimistic and believe that the level of student success will increase.

More detailed information on the data is available at the site:http://www.ii.ua.pt/ccpsf/research/isabelhuet/en/home.ht m.

\section{ACKNOWLEDGMENT}

The authors express their gratitude for assistance from the lecturers from the Informatics and Telecommunication Department at Aveiro who taught the course 'Programming I' and the lecturers from the Department of Computer and Information Sciences at Strathclyde who taught the course 'Programming Foundations'. Similarly, we thank the students at both institutions who participated in this study.

This research is supported by the Research Unit 'Development of Pedagogic Knowledge in Education and Training Systems' at the University of Aveiro, the Foundation for Science and Technology (Portugal) and the Luso-American Foundation.

\section{REFERENCES}

Session T2G

[1] R. T. Blackburn and J. H. Lawrence, Faculty at Work. Baltimore: The Johns Hopkins University Press, 1995.

[2] C. E. Brawner, R. M. Felder, R. H. Allen, and R. Brent, "How important is effective teaching to engineering faculty and administrators," presented at American Society for Engineering Education Annual Conference \& Exposition, 2002.

[3] A. T. Chamillard and K. A. Braun, "Evaluating programming ability in an introductory computer science course," presented at Thirty-First SIGCSE Technical Symposium on Computer Science Education, Austin, Texas, 2000.

[4] P. A. Cohen, "Effectiveness of student-rating feedback for improving college instruction: a meta-analysis of findings," Research in Higher Education, pp. 321-341, 1980.

[5] M. Davis, "Barriers to reflective practice: the changing nature of higher education," Active Learning in Higher Education, vol. 4, pp. 243-255, 2003

[6] R. Felder and L. Silverman, "Learning and teaching styles in engineering education," Engineering Education, vol. 78, pp. 674-681, 1988.

[7] R. Felder, D. Woods, J. Stice, and A. Rugarcia, "The future of engineering education II. Teaching methods that work.," Engineering Education, vol. 34, pp. 26-39, 2000.

[8] R. Higgins, P. Hartley, and A. Skelton, "Getting the message across: the problem of communicating assessment feedback," Teaching in Higher Education, vol. 6, pp. 269-275, 2001.

[9] I. Huet, O. Pacheco, and J. Tavares, "Effects of curriculum adjustments on first-year programming courses: students' performance and achievement," presented at 33rd Frontiers in Education Conference, Boulder, Colorado, 2003.

[10] I. Huet, J. Tavares, G. Weir, J. Ferguson, and J. Wilson, "Co-operation in education: the teaching and learning of programming at the Universities of Aveiro and Strathclyde," presented at ICHED conference, Aveiro, Portugal, 2003.

[11] I. Huet, A. P. Cabral, and J. Makinnen, "Intervention programs in higher education: innovative approaches and strategies," presented at European Conference of Educational Research (ECER), University of Hamburg, 2003.

[12] D. A. Kolb, Experiential learning: experience as the source of learning and development. New Jersey: Prentice-Hall Inc., 1984.

[13] S. Male, W. Lawrance, and S. Flintoff, "Support schemes for first year computing students and electrical and computer engineering students at Curtin University of Technology," presented at Teaching and Learning Forum 2002: Focusing on the Students, 2002.

[14] H. W. Marsh, "Validity of students' evaluations of college teaching: a multitrait-multimethod analysis," Journal of Educational Psychology, vol. 74, pp. 264-279, 1982.

[15] M. Melo, J. Silva, Á. Gomes, and F. Vieira, "Concepções de pedagogia universitária - uma análise do questionário de avaliação do ensino ministrado na Universidade do Minho," in Revista Portuguesa de Educação, vol. 13, 2000, pp. 125-157.

[16] M. Prosser, P. Ramsden, K. Trigwell, and E. Martin, "Dissonance in experience of teaching and its relation to the quality of student learning," Studies in Higher Education, vol. 28, pp. 37-48, 2003.

[17] P. Ramsden, Learning to Teach in Higher Education: London, Routledge., 1992.

[18] P. Ramsden, D. Margetson, E. Martin, and S. Clarke, "Recognising and rewarding good teaching in Australian higher education (final report)," vol. 2003: Griffith Institute of Higher Education, 1995. 
[19] P. Rosati, "Students' psychological type and success in different engineering programs," presented at ASEE/IEEE Frontiers in Education Conference, Boulder, Colorado, 2003.

[20] A. Saroyan and C. Amundsen, "Evaluating university teaching: time to take stock," Assessment \& Evaluation in Higher Education, vol. 26, pp. 341-353, 2001.

[21] D. Schön, The reflective practitioner. London: Basic Books, 1983.

[22] D. M. Shannon, D. J. Twale, and G. R. Hancock, "Use of instructional feedback and modification methods among university faculty," Assessment \& Evaluation in Higher Education, vol. 21, pp. 41-53, 1996.

[23] J. Tavares, I. Brzezinski, I. Huet, A. Cabral, and D. Neri, "'Having coffee" with professors and students to talk about higher education pedagogy and academic success," presented at 24th International HERDSA Conference, NewCastle, Australia, 2001

[24] L. Thomas, M. Ratcliffe, J. Woodbury, and E. Jarman, "Learning styles and performance in introductory programming sequence," SIGCSE Bulletin, vol. 34, pp. 33-37, 2002.

[25] P. Wankat and F. Oreovicz, Teaching engineering: New York: McGraw-Hill, 1993.

[26] L. Winkvit, "Higher education and the proposed European Constitution", Perspective, vol. 9 (2), October, 2005.

[27] R. M. Felder, D. R. Woods, J. E. Stice and A. Rugarcia, "The future of engineering education II". Teaching methods that work. Chemical Engineering Education, vol. 34 (1), pp. 26-39, 2000.

[28] R. Yin, Case study research: design and methods, 2nd ed. ed. Beverly Hills, CA: Sage Publishing., 1994. 